\title{
Electrolytic lesions of the dorsal hippocampus disrupt renewal of conditional fear after extinction
}

\author{
Jinzhao ji' and Stephen Maren 1,2,3 \\ ${ }^{1}$ Department of Psychology and ${ }^{2}$ Neuroscience Program, University of Michigan, Ann Arbor, Michigan 48109, USA
}

\begin{abstract}
There is a growing body of evidence that the hippocampus is critical for context-dependent memory retrieval. In the present study, we used Pavlovian fear conditioning in rats to examine the role of the dorsal hippocampus (DH) in the context-specific expression of fear memory after extinction (i.e., renewal). Pre-training electrolytic lesions of the DH blunted the expression of conditional freezing to an auditory conditional stimulus (CS), but did not affect the acquisition of extinction to that CS. In contrast, DH lesions impaired the context-specific expression of extinction, eliminating the renewal of fear normally observed to a CS presented outside of the extinction context. Post-extinction DH lesions also eliminated the context dependence of fear extinction. These results are consistent with those using pharmacological inactivation of the $\mathrm{DH}$ and suggest that the $\mathrm{DH}$ is required for using contextual stimuli to regulate the expression of fear to a Pavlovian CS after extinction.
\end{abstract}

It has been recognized for decades that the expression of memory depends on the context in which memory is retrieved (Spear 1973; Tulving and Thomson 1973). Contextual retrieval operates on both declarative memory in humans (Maguire et al. 1997) and Pavlovian conditioning in animals (Bouton 1993; Maren and Holt 2000). And despite the importance of contextual retrieval in normal memory function, little is known concerning its brain mechanisms.

The hippocampus has a critical role in several memory processes, including episodic memory (for reviews, see Squire and Zola 1996; Eichenbaum 2000). Years ago it was suggested that the hippocampus has an important role in contextual memory retrieval (Hirsh 1974). Consistent with this view, an abundance of studies implicate the hippocampus not only in encoding contextual representations (Kim and Fanselow 1992; Phillips and LeDoux 1992; Maren et al. 1997; Frankland et al. 1998; Good et al. 1998; Rudy and O'Reilly 2001), but also in using these representations in the service of memory retrieval (Good and Honey 1991; Honey and Good 1993; Kennedy and Shapiro 2004). We have recently shown in a series of experiments using intrahippocampal muscimol infusions that the dorsal hippocampus $(\mathrm{DH})$ plays an important role in the context-dependent retrieval of fear memory in two different Pavlovian interference paradigms: latent inhibition (Holt and Maren 1999) and extinction (Corcoran and Maren 2001, 2004). Both procedures yield context-dependent memory, insofar as conditional responding is low in the pre-exposure or extinction contexts and high outside of those contexts. Reversible inactivation of the DH prior to retrieval testing eliminates the renewal of fear to a CS outside of the pre-exposure or extinction context, without affecting fear expression per se or context discrimination.

Reversible lesions reveal an important role for the $\mathrm{DH}$ in the context specificity of latent inhibition and extinction. Earlier studies, however, using permanent hippocampal lesions found that electrolytic lesions of the fimbria/fornix (Wilson et al. 1995) or neurotoxic lesions of the entire hippocampus (Frohardt et al. 2000) had no effect on the context-dependent expression of extinction. It may be the case that the nature (reversible vs. permanent) and timing (pre-training vs. pre-testing) of the lesions is an

\section{${ }^{3}$ Corresponding author.}

E-mail maren@umich.edu; fax (734) 763-7480.

Article and publication are at http://www.learnmem.org/cgi/doi/10.1101/ Im.91705. important determinant of their effects on the context dependence of extinction. Indeed, lesions and reversible inactivation may yield different behavioral outcomes, as other neural systems may compensate for irreversible damage, and the timing of hippocampal manipulation is critical in determining hippocampal deficits in contextual fear conditioning (Maren et al. 1997). Thus, in the present study, we used Pavlovian fear conditioning in rats to examine the effects of electrolytic lesions made either before conditioning or after extinction on the context specificity of extinction. Because recent data suggest that the method for testing context-specific fear memory may affect hippocampal involvement in extinction (Corcoran and Maren 2004), we also examined the renewal of extinction either in a neutral context (Experiment 1) or in the conditioning context (Experiment 2). Our results reveal that electrolytic lesions of the DH disrupt the context dependence of extinction independent of when they are made relative to extinction, and independent of the context in which the renewal of extinguished fear is tested.

\section{Results}

Experiment 1: Pre- or post-extinction dorsal hippocampal lesions and renewal testing in a neutral context

The expression of extinguished fear is context-dependent. If a CS is presented in its extinction context, then rats retrieve an extinction memory and exhibit low levels of freezing. Alternatively, if retrieval testing occurs in a context that is different from the extinction context, then rats retrieve the conditioning memory and exhibit a renewal of conditional freezing (Bouton 1993; Westbrook et al. 2000). Reversible inactivation of the DH with intrahippocampal muscimol infusion blocks the contextdependent retrieval of extinction when testing occurs in a context that has no history of CS exposure (i.e., a neutral context) (Corcoran and Maren 2001, 2004). The aim of this experiment was to elucidate whether memory retrieval in a neutral context is sensitive to electrolytic DH lesions. Because the timing of DH lesions has dissociable effects on contextual fear conditioning, we compared pre- and post-extinction electrolytic DH lesions on contextual retrieval of fear extinction.

\section{Histology}

Histological reconstruction of a representative electrolytic DH lesion is shown in Figure 1. The lesion consisted of bilateral dam- 


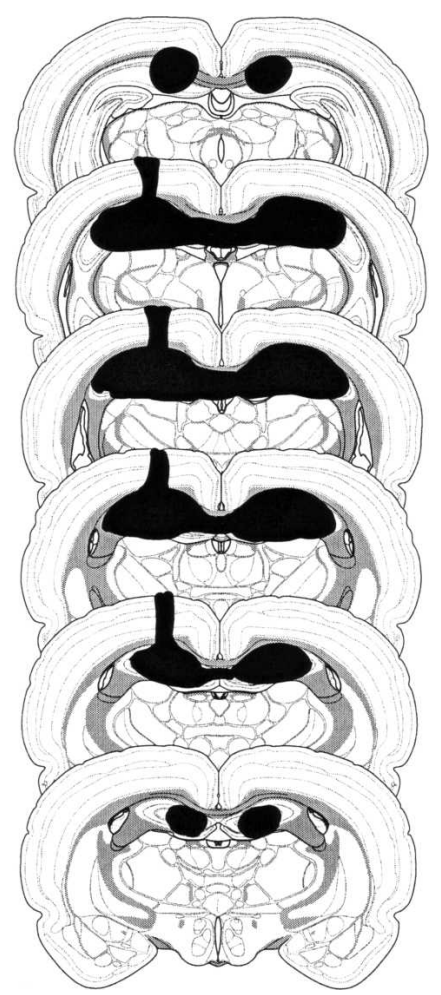

Figure 1. Schematic representation of a representative electrolytic dorsal hippocampal lesion. Reconstruction of the lesion was made on rat atlas templates adapted with permission from Elsevier ( $) 1992$, Swanson (1992).

age to hippocampal areas CA1 and CA3, the dentate gyrus, and the rostral aspect of the dorsal subiculum. There was minor extrahippocampal damage to the neocortex overlying the hippocampus and lesions also damaged axonal tracts (fimbria/fornix, alveus, corpus callosum) in the vicinity of the lesion.

\section{Behavior}

\section{Fear conditioning}

Rats were either trained in one context (context A) and extinguished in a different context (context $\mathrm{B}$ ), or trained and extinguished in the same context (context A) prior to retrieval testing in context $\mathrm{B}$. Hence, some rats were tested for fear of the tone CS in the extinction context (SAME; ABB, where each letter denotes the context of conditioning, extinction, and testing), whereas others were tested for fear of the tone CS outside of the extinction context (DIFF; AAB). In this case, the test context was neutral, insofar as it had never hosted fear conditioning. Exposure to all contexts was equated, and the physical contexts serving as A and B were counterbalanced.

Freezing during the conditioning sessions is shown in Figure 2A. Immediate post-shock freezing increased significantly across the five conditioning trials on the conditioning day $\left(F_{(7,581)}=303.45, p<0.001\right)$. Pre-training electrolytic DH lesions (DH-Pre) attenuated post-shock freezing. ANOVA demonstrated that there was a significant main effect of lesion $\left(F_{(2,83)}=3.90\right.$, $p<0.05)$ and a significant interaction of lesion and training trial $\left(F_{(14,581)}=3.42, p<0.001\right)$. Planned comparisons indicated that the DH-Pre group exhibited significantly lower freezing than the sham (SH) group after the first $(p<0.001)$ and second $(p<0.05)$ conditioning trials and significantly lower freezing than the postextinction DH lesions (DH-Post) group after the first conditioning trial $(p<0.001)$, but not after later trials. Thus, DH-Pre rats were able to acquire post-shock freezing after five conditioning trials.

\section{Extinction}

Conditional freezing evoked by the tone CS over the course of extinction training is shown in Figure 2B. The average freezing during the 1-min period following each of the first four tone CS-alone presentations on each extinction day is shown. Freezing to the tone CS declined significantly across the three extinction days $\left(F_{(2,166)}=111.35, p<0.001\right)$. The ANOVA indicated that pre-training lesions affected the overall freezing of the group during the extinction days $\left(F_{(2,83)}=8.11, p<0.001\right)$, but also revealed a nonsignificant interaction of extinction day and lesion $\left(F_{(4,166)}=0.43, p=0.78\right)$. Post hoc analysis $(p<0.05)$ showed for each extinction day rats in the DH-Pre group exhibited significantly lower levels of freezing than rats in the $\mathrm{SH}$ and DH-Post groups, which did not differ from one another. These results suggest that the rate of extinction was independent of lesion treatment although pre-training electrolytic DH lesions reduced extinction freezing. Importantly, there was no difference in extinction rate or magnitude between animals in the SAME and DIFF conditions. This was verified by the ANOVA demonstrating that there were no significant main effect of context
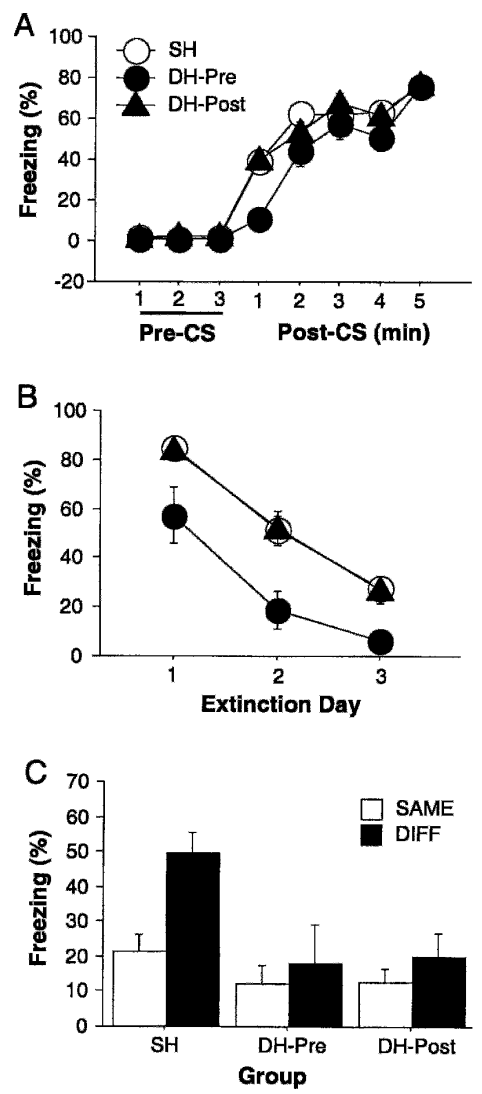

Figure 2. Effects of $D H$ lesions on $A B B / A A B$ renewal. $(A)$ Mean ( \pm SEM) percentage of freezing exhibited on the conditioning day, with 3 min prior to tone CS onset (baseline) and 1 min post-CS for five trials. All rats were fear conditioned in context A. (B) Extinction to the tone CS. Mean $( \pm$ SEM) percentage of freezing for the first four CS presentations across the $3 \mathrm{~d}$ of extinction in contexts $A$ and $B$. (C) Mean ( \pm SEM) percentage of freezing for the first 4 min after CS onset during test. Rats were tested for fear of CS in a neutral context, either in the extinction context (SAME; $A B B$; open bars) or outside of the extinction context (DIFF; AAB; filled bars). Electrolytic $\mathrm{DH}$ or sham (SH) lesions were made either before training (DH-Pre) or after extinction (DH-Post). 
$\left(F_{(1,84)}=1.04, p=0.31\right)$ and no significant interaction of extinction day and context $\left(F_{(2,168)}=1.91, p=1.52\right)$ (data not shown).

\section{Renewal}

Renewal testing occurred outside of conditioning context, either in a context the same as the extinction context (SAME; ABB) or in a context different from the extinction context (DIFF; AAB). For consistency, the average freezing for the first $4 \mathrm{~min}$ of the 8-min continuous tone CS (freezing during the first $4 \mathrm{~min}$ after tone onset was normalized by subtracting rats' pre-tone freezing) is illustrated in Figure 2C. The main effects of lesion $\left(F_{(2,80)}=7.05\right.$, $p<0.01)$ and test context $\left(F_{(1,80)}=5.76, p<0.05\right)$ for the test data were highly significant. Although there was no significant interaction of lesion and test context $\left(F_{(2,80)}=2.11, p=0.13\right)$, planned comparisons showed that $\mathrm{SH} / \mathrm{DIFF}$ rats had much higher freezing levels than SH/SAME rats $(p<0.001)$, whereas there were no differences between DH-Pre/SAME and DH-Pre/DIFF, and between DH-Post/SAME and DH-Post/DIFF groups. Thus, renewal occurred when intact rats were tested outside the extinction context and electrolytic lesions either before conditioning or after extinction disrupted renewal. It is worth noting that the deficits in renewal in rats with DH lesions were not likely due to a problem in generating freezing to an auditory CS, insofar as freezing to the CS in the DH-Pre rats was quite high during the first extinction session (see Fig. 2B).

\section{Experiment 2: Pre-training electrolytic dorsal hippocampal lesions and renewal testing in the conditioning context}

Previous studies found no effect of pre-training lesions of the fornix or hippocampus on renewal using a bar-press suppression procedure when rats were tested in the conditioning context (ABA) (Wilson et al. 1995; Frohardt et al. 2000). The first experiment in the present study indicated that electrolytic lesions made either before training or after extinction affected $A A B$ renewal, a paradigm in which retrieval testing occurs in a context that has no history of conditioning (Corcoran and Maren 2004). Because $\mathrm{AAB}$ and $\mathrm{ABA}$ renewal, assessed by conditional freezing, are differentially sensitive to $\mathrm{DH}$ muscimol infusions (Corcoran and Maren 2004), it is critical to determine whether ABA renewal is sensitive to pre-training electrolytic DH lesions. To equate the post-surgery recovery period of rats receiving post-extinction lesions in Experiment 1, rats were allowed $7 \mathrm{~d}$ of rest between extinction and retrieval testing in this experiment.

\section{Behavior}

\section{Fear conditioning}

Rats were either trained in one context (context A) and extinguished in a different context (context $B$ ), or trained and extinguished in the same context (context A) prior to retrieval testing in context A. Hence, some rats were tested for fear of the CS in the extinction context (SAME; AAA), whereas others were tested for fear of the CS outside of the extinction context (DIFF; ABA). In both cases, the test context was the same as the context used for fear conditioning. Exposure to all contexts was equated and the physical contexts serving as A and B were counterbalanced.

Freezing on the conditioning day is shown in Figure 3A. Pre-training electrolytic DH lesions attenuated post-shock freezing, revealed by a significant interaction of training trials and lesion $\left(F_{(7,189)}=2.53, p<0.05\right)$. There was no significant main effect of lesion $\left(F_{(1,27)}=0.32, p=0.58\right)$. Not surprisingly, immediate post-shock freezing increased significantly across the five trials on the conditioning day $\left(F_{(7,189)}=99.65, p<0.001\right)$.
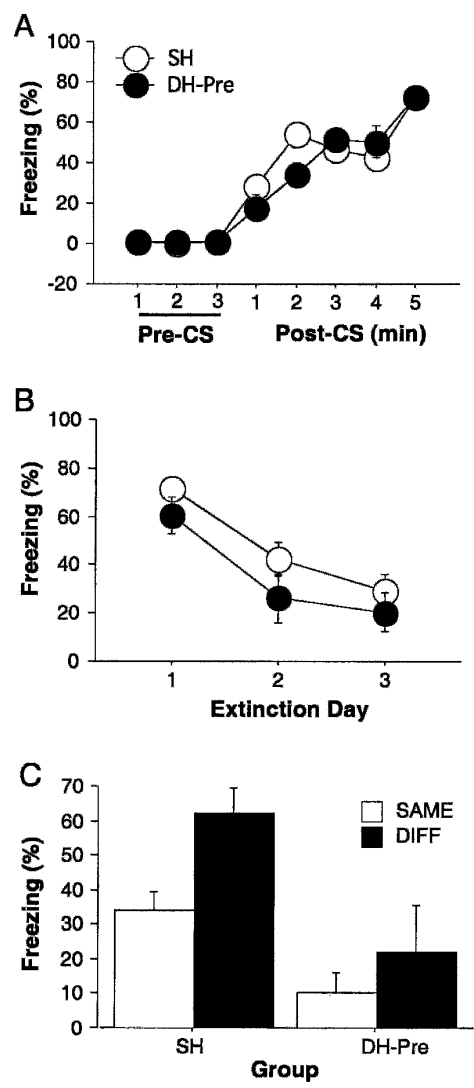

Figure 3. Effects of $D H$ lesions on $A A A / A B A$ renewal. $(A)$ Mean ( $\pm S E M)$ percentage of freezing exhibited on the conditioning day, with 3 min prior to tone CS onset (baseline) and 1 min post-CS for five trials. All rats were fear conditioned in context A. (B) Extinction to the tone CS. Mean $( \pm$ SEM) percentage of freezing for the first four CS presentations across the $3 \mathrm{~d}$ of extinction in contexts $A$ and $B$. (C) Mean ( \pm SEM) percentage of freezing for the first 4 min after CS onset during test. Rats were tested for fear of CS in the conditioning context, either in the extinction context (SAME; AAA; open bars) or outside of the extinction context (DIFF; ABA; filled bars). Electrolytic $\mathrm{DH}$ (DH-Pre) or sham (SH) lesions were made before conditioning.

\section{Extinction}

The average freezing for the 1-min period after the first four auditory CS-alone presentations of each extinction is shown in Figure $3 \mathrm{~B}$. The ANOVA demonstrated that there was no significant main effect of lesion $\left(F_{(1,27)}=2.22, p=0.15\right)$ and no significant interaction of extinction day and lesion $\left(F_{(2,54)}=0.22, p=0.80\right)$. The results suggest that the rate of extinction was independent of lesion treatment. Unlike Experiment 1, pre-training DH lesions did not attenuate freezing to the auditory CS. Importantly, there was no difference in either the rate or magnitude of extinction in the SAME and DIFF conditions. This was verified by a nonsignificant main effect of context $\left(F_{(1,27)}=2.17, p=0.15\right)$ and a nonsignificant interaction of extinction day and context $\left(F_{(2,54)}=0.31, p=0.73\right)$ (data not shown).

\section{Renewal}

Renewal testing occurred in the conditioning context, either in the same context as the extinction context (SAME; AAA) or in a different context (DIFF; ABA). For consistency, the average freezing for the first 4 min of the 8-min continuous tone CS (freezing during the first $4 \mathrm{~min}$ after tone onset was normalized by subtracting rats' pre-tone freezing) is illustrated in Figure 3C. The main effects of lesion $\left(F_{(1,25)}=14.16, p<0.001\right)$ and test context

\section{Learning \& Memory \\ www.learnmem.org}


$\left(F_{(1,25)}=5.55, p<0.05\right)$ on the test data were highly significant. There was not a significant interaction of lesion and test context $\left(F_{(1,25)}=0.93, p=0.34\right)$. However, planned comparisons showed that SH/SAME froze significantly less than SH/DIFF rats $(p<0.05)$, whereas there were no differences between the DHPre/SAME and DH-Pre/DIFF groups. Thus, when intact rats were tested outside the extinction context, renewal occurred. As in Experiment 1, pre-training electrolytic lesions disrupted renewal. The data reveal that pre-training DH lesions disrupt memory retrieval of fear after extinction independent of whether testing occurred in a neutral context (Experiment 1) or the conditioning context (this experiment).

\section{Pre-training electrolytic DH lesions and context discrimination}

During the extinction phase of Experiments 1 and 2, exposure to each context was equated. Therefore, half of the rats (ABB or $\mathrm{ABA}$ ) were returned to the conditioning context (COND), and the other half (AAB or AAA) was placed in a novel context (NOVEL) to equate exposure to the other (extinction) contexts. This allowed us to assess the effect of pre-training DH lesions on contextual discrimination (conditioning context vs. novel context).

The average freezing for the first $8 \mathrm{~min}$ of context exposure on the first equilibration day is shown in Figure 4 . The main effects of lesion $\left(F_{(2,109)}=4.88, p<0.01\right)$ and equilibration $\left(F_{(1,109)}=22.61, p<0.001\right)$ for context discrimination were highly significant. There was no significant interaction of lesion and equilibration $\left(F_{(2,109)}=0.46, p=0.63\right)$. Planned comparisons $(p<0.05)$ showed that SH/COND and DH-Post/COND rats had much higher freezing levels than SH/NOVEL and DH-Post/ NOVEL rats, and DH-Pre/COND rats had nearly significant higher levels of freezing than DH-Pre/NOVEL rats $(p=0.076)$. This indicated that context discrimination was relatively unaffected by pre-training electrolytic DH lesions.

\section{Discussion}

The present experiments demonstrate that electrolytic DH lesions disrupt the context specificity of extinction, independent of whether lesions were made before training or after extinction (Experiment 1) and independent of where retrieval testing occurred (Experiments 1 and 2). These results are consistent with previous reports using reversible hippocampal lesions that the DH plays a role in contextual fear memory retrieval (Holt and Maren 1999; Corcoran and Maren 2001, 2004). It is important to note that the effects of hippocampal damage on fear renewal are not due to impairments in CS-US memory retrieval or the ability

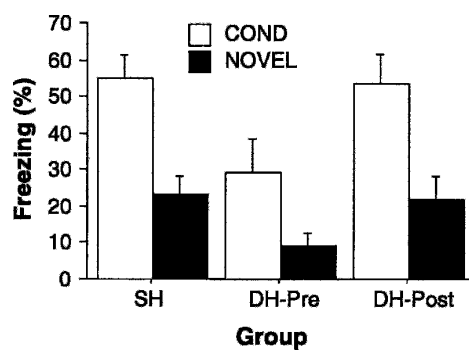

Figure 4. Effects of $\mathrm{DH}$ lesions on context discrimination. Mean ( \pm SEM) percentage of freezing for the first 8 min of context exposure on the first equilibration day. All rats were fear conditioned in context $A$. Exposure was either in the same context as the conditioning context (COND, open bars) or in a novel context (NOVEL, filled bars). Electrolytic $\mathrm{DH}$ or sham (SH) lesions were made either before training (DH-Pre) or after extinction (DH-Post). to perform the freezing response. Also, contextual discrimination (an index of context processing) was relatively unaffected by hippocampal lesions, suggesting that the renewal deficits are due to impairments in either contextual encoding or retrieval (not in the representation or discrimination of contexts per se).

The present study found that pre-training and postextinction DH lesions were equally effective in disrupting renewal. This is in contrast with the typically stronger effects of post-training DH lesions on context fear (Maren et al. 1997). Specifically, rats with pre-training DH lesions acquire contextual fear normally, but rats that receive DH lesions shortly after fear conditioning exhibit robust impairments in contextual fear. This indicates that the timing of hippocampal lesions is crucial in some behavioral tasks (such as contextual fear conditioning) but not in others (such as acquisition or expression of contextspecific extinction). And similar to other studies (e.g., Maren et al. 1997), there was a tendency for DH lesions to attenuate conditional freezing to the auditory CS. In the present study, the deficit in auditory freezing was only reliable in Experiment 1; subtle differences in the lesions, the age of the rats, and the procedures used in the experiments, for example, may have accounted for this difference between Experiments 1 and 2 in this regard. It has been previously reported that electrolytic lesions of the hippocampus produce hyperactivity (Roberts et al. 1962; Shull and Holloway 1985; Maren and Fanselow 1997; Maren et al. 1997). Therefore, the freezing deficits observed in rats with DH lesions could be due to hyperactivity (i.e., increased motor activity). Nonetheless, the relationship between motor activity and freezing has been examined and found to provide an inadequate account of freezing deficits in rats with hippocampal damage (Maren and Fanselow 1997; Maren et al. 1997). For example, locomotor activity and freezing do not correlate with one another in intact rats or in rats with hippocampal damage (Maren and Fanselow 1997; Maren et al. 1997). Moreover, rats with hippocampal lesions do not show suppression of activity after fear conditioning (Maren et al. 1998). Therefore, it is unlikely that motor hyperactivity accounts for the conditional freezing deficits in rats with $\mathrm{DH}$ lesions. In both experiments, extinction rate to the auditory CS was relatively unaffected by $\mathrm{DH}$ lesions, and the effects of DH lesions on tone fear and renewal were dissociable.

Collectively, these results corroborate earlier work using reversible hippocampal inactivation to define a role of the hippocampus in contextual memory retrieval in Pavlovian conditioning paradigms (Holt and Maren 1999; Corcoran and Maren 2001, 2004). Specifically, Holt and Maren (1999) found that intrahippocampal infusions of muscimol attenuated the context-specific expression of latent inhibition, indicating that the $\mathrm{DH}$ is required for contextual retrieval cues to disambiguate CS-US and CS-no event associations in latent inhibition. More recently, Corcoran and Maren $(2001,2004)$ found that intrahippocampal muscimol infusions impaired the contextual retrieval of fear after extinction, which has similarities to latent inhibition. Together with the present work, these studies provide strong support for the role of the hippocampus in contextual memory retrieval, a concept first proposed by Hirsh (1974). Hirsh (1974) posited two models for information storage in the nervous system. In the associative model, he imagined that information was stored along the "performance line," which is not dependent on the hippocampus. In the retrieval model, memories are "indexed" by the hippocampus according to the contextual cues present when learning takes place and stored off the performance line. In a situation in which a stimulus has more than one meaning, the hippocampus uses the contextual index to retrieve the meaning of that stimulus associated with the retrieval context. In the absence of a functional hippocampus (e.g., after hippocampal le- 
sions in the present experiments), performance reverts to the associative model and is governed by the net associative strength supported by the excitatory CS-US and CS-no US associations (Hirsh 1974; Maren and Holt 2000).

In contrast to the present results, however, Bouton and colleagues have reported that pre-training electrolytic lesions of the fimbria/fornix (Wilson et al. 1995) or neurotoxic hippocampal lesions (Frohardt et al. 2000) do not affect renewal in a bar-press suppression paradigm. One possible explanation for this discrepancy is the different functional consequence of fornix or total hippocampal lesions compared to electrolytic DH lesions. Fornix lesions disconnect the hippocampus from subcortical structures, whereas excitotoxic lesions of the hippocampus spare fibers of passage but destroy hippocampal neurons. In contrast, electrolytic DH lesions disrupt both fibers of passage connecting the hippocampus to subcortical structures, as well as damaging neurons in the DH. It is, therefore, conceivable that electrolytic DH lesions have greater effects on contextual memory retrieval than either fornix or neurotoxic hippocampal lesions. Another possibility is that different fear response measures (e.g., suppression vs. freezing) are differentially sensitive to hippocampal damage. Bouton and colleagues used bar-press suppression (Wilson et al. 1995; Frohardt et al. 2000), whereas we used freezing to index fear. These responses are neuroanatomically dissociable, and rats can continue to suppress in the absence of freezing under some conditions (Amorapanth et al. 1999).

In recent work from our laboratory, we reported that the context in which fear memory is assessed after extinction could affect the degree of sensitivity of that memory to hippocampal muscimol infusions. Specifically, AAB renewal is more sensitive than ABA renewal to hippocampal inactivation (Corcoran and Maren 2004). This contrasts with the present results, which show that $\mathrm{AAB}$ and $\mathrm{ABA}$ renewal are equally sensitive to hippocampal lesions. However, there are several differences between our earlier work and the present study that might account for the discrepant results. One possibility is that lesions and reversible inactivation yield different behavioral outcomes, because lesions clearly disrupt more neurochemical systems than muscimol alone. Second, the timing of hippocampal manipulations can be critical in determining the behavioral outcomes under some conditions (e.g., contextual fear conditioning) (Maren et al. 1997). In the present study, lesions in the ABA experiment (Experiment 2) were made 1 wk before training, which contrasts with the pre-testing DH inactivation used by Corcoran and Maren (2004).

Our data also demonstrate that pre-training DH lesions selectively disrupt contextual retrieval without impairing contextual discrimination. Rats with DH lesions were able to discriminate the conditioning context and a novel context $24 \mathrm{~h}$ after the conditioning day. This is consistent with a previous report that inactivation of the DH selectively impairs contextual retrieval without affecting the expression of a contextual discrimination (Holt and Maren 1999). In another study, Frankland et al. (1998) found that pre-training DH lesions produced deficits in contextual discriminations under some circumstances. This discrepancy is best explained by the different conditioning protocols used in the present study and the Frankland et al. (1998) study. Here we used five conditioning trials followed by extinction trials in highly discriminable contexts, whereas Frankland et al. (1998) used alternating single-trial shock sessions and shock-free sessions with less discriminable contexts.

The present results are consistent with a large volume of work implicating the hippocampus in episodic memory retrieval (Eichenbaum 2000; Kennedy and Shapiro 2004). Rats with hippocampal damage exhibit deficits in memory retrieval for socially transmitted food preference (Winocur 1990; Eichenbaum et al. 1999). Also, transection of the fornix or neurotoxic lesions of the hippocampus disrupt context-dependent memory retrieval and a variety of appetitively motivated tasks (Hirsh 1974; Honey and Good 1993; Kennedy and Shapiro 2004). There is emerging evidence that hippocampal place cell firing during the sequence of events and places that composes episodic memory is also context-specific (Anderson and Jeffery 2003; Hayman et al. 2003; Jeffery et al. 2004; Yeshenko et al. 2004).

In addition, lesion and neuroimaging data from humans have implicated the hippocampus in the retrieval of contextdependent episodic memory (Vargha-Khadem et al. 1997; Eldridge et al. 2000; Burgess et al. 2001; Holdstock et al. 2002, 2005; Addis et al. 2004). For example, by combining event-related functional magnetic resonance imaging (efMRI) and a virtual reality paradigm, Burgess et al. (2001) found that retrieval of contextdependent episodic memory elicits hippocampal activity. Furthermore, memory recollection modulates hippocampal activation during episodic memory retrieval (Addis et al. 2004), suggesting that the hippocampus is engaged by retrieving the source (the context) in which a memory is encoded (Davachi et al. 2003). Lesion studies from humans also indicate that selective damage of the hippocampus produces a severe impairment in context-dependent episodic memory retrieval while generally sparing context-free semantic memory (Vargha-Khadem et al. 1997) or item recognition (Holdstock et al. 2002, 2005).

In conclusion, a convergence of data from many behavioral paradigms in animals and humans validates a role for the hippocampus in contextual memory retrieval. Together with previous inactivation studies, this work bolsters the critical role for the hippocampus in memory retrieval. The context-dependent modulation of the conditional fear response after extinction may involve the interaction between the hippocampus and amygdala (Hobin et al. 2003). Further work is in progress to examine this possibility.

\section{Materials and Methods}

\section{Experiment 1: Pre- or post-extinction dorsal hippocampal lesions and renewal testing in a neutral context}

\section{Subjects}

The subjects were 96 adult male Long-Evans rats (200-224 g) obtained from a commercial supplier (Harlan Sprague Dawley). After arrival, the rats were housed individually in plastic hanging cages on a 14-h light/10-h dark cycle (lights on at 7:00 a.m.) and had free access to food and water. After individual housing, the rats were handled (10-20 sec per rat per day) for $5 \mathrm{~d}$ to habituate them to the experimenter.

\section{Surgery}

The rats were treated with atropine methyl nitrate $(\approx 0.04 \mathrm{mg} / \mathrm{kg}$, i.p.), anesthetized with sodium pentobarbital (Nembutal; $65 \mathrm{mg}$ / $\mathrm{kg}$, i.p.), and mounted in a Kopf stereotaxic apparatus (Kopf Instruments). The scalp was incised and retracted, and the head was positioned to place bregma and lambda in the same horizontal plane. Small holes ( $2 \mathrm{~mm}$ diameter) were drilled through the skull for the placement of a stainless-steel electrode insulated with Epoxylite except for $0.5 \mathrm{~mm}$ at the tip. Bilateral electrolytic lesions were made in $\mathrm{DH}(2.8 \mathrm{~mm}$ posterior, $2.0 \mathrm{~mm}$ lateral, $4.0 \mathrm{~mm}$ ventral to bregma; $4.2 \mathrm{~mm}$ posterior, $3.0 \mathrm{~mm}$ lateral, $4.0 \mathrm{~mm}$ ventral to bregma). Electrolytic lesions were made with anode, constant direct current at each location $(1.2 \mathrm{~mA}$ for $12 \mathrm{sec}$ ) (Maren et al. 1997). No electrodes were implanted during sham surgery. Following surgery, the incision was closed with stainless-steel wound clips, and the rats were allowed to recover on a heating pad before returning to their home cage.

\section{Behavioral apparatus}

Eight identical observation chambers $(30 \times 24 \times 21 \mathrm{~cm}$; MEDAssociates) were used in all experiments. The chambers were con-

\section{Learning \& Memory \\ www.learnmem.org}


structed of aluminum (side walls) and Plexiglas (rear wall, ceiling, and hinged front door) and were situated in sound-attenuating cabinets located in a brightly lit and isolated room. The floor of each chamber consisted of 19 stainless steel rods ( $4 \mathrm{~mm}$ in diameter) spaced $1.5 \mathrm{~cm}$ apart (center-to-center). Rods were wired to a shock source and solid-state grid scrambler (MED-Associates) for the delivery of footshock USs. A speaker mounted outside a grating in one wall of the chamber was used for the delivery of acoustic CSs.

Each conditioning chamber rested on a load-cell platform that was used to record chamber displacement in response to each rat's motor activity. To ensure interchamber reliability, we calibrated each load-cell amplifier to a fixed chamber displacement. The output of each chamber's load cell was set to a gain that was optimized for detecting freezing behavior (somatomotor immobility, except that necessitated by breathing) (Maren 1998). Load-cell amplifier output $(-10$ to $+10 \mathrm{~V})$ from each chamber was digitized and acquired on-line using Threshold Activity software (MED-Associates). Absolute values of the load-cell voltages (load-cell V) were computed and multiplied by 10 to yield a loadcell activity scale that ranged from 0 to 100 . For each chamber, load-cell $\mathrm{V}$ was digitized to $5 \mathrm{~Hz}$, yielding one observation per rat every $200 \mathrm{msec}$ (300 observation/rat/min). Freezing was quantified by computing the number of observations for each rat that had a value less than the freezing threshold (load-cell activity $=5$; animals exhibit freezing when load cell activity is at or below this value) (Maren 1998). To avoid counting momentary inactivity as freezing, we only scored an observation as freezing if it fell within a continuous group of at least five observations that were all less than the freezing threshold. Thus, freezing was only scored if the rat was immobile for at least $1 \mathrm{sec}$. For each session, the freezing observations were transformed to a percentage of total observations.

Two distinct contexts were used in this experiment. For the first context, a $15 \mathrm{~W}$ houselight mounted opposite the speaker was turned on, and room lights remained on. The chambers were cleaned with a $1 \%$ acetic acid solution. To provide a distinct odor, stainless steel pans containing a thin layer of this solution were placed underneath the grid floors before the rats were placed inside. Ventilation fans in each chest supplied background noise ( $65 \mathrm{~dB}$, A scale). Rats were transported to this context in white plastic boxes. For the second context, all room and chamber houselights were turned off; a pair of $40 \mathrm{~W}$ red lights provided illumination. Additionally, the doors on the soundattenuating cabinets were closed, the ventilation fans were turned off, and the chambers were cleaned with a $1 \%$ ammonium hydroxide solution. Also, stainless steel pans containing a thin layer of the same solution were placed underneath the grid floors before the rats were placed inside to provide a distinct odor. Rats were transported to this context in black plastic boxes.

\section{Procedure}

All rats received either pre-training lesions or post-extinction lesions aimed at the $\mathrm{DH}$. The rats were allowed $7 \mathrm{~d}$ to recover after surgery. Therefore, there was a 7-d interval between extinction and retrieval testing for rats with post-extinction DH lesions. To equate the post-surgery recovery period of rats receiving postextinction lesions, rats with pre-training $\mathrm{DH}$ lesions were allowed $7 \mathrm{~d}$ of rest between extinction and retrieval testing. Sham rats in each time point lesion (pre-training or post-extinction) were collapsed to form one control group $(\mathrm{SH})$ because there were no significant differences between the groups during training $(p=0.41)$, extinction $(p=0.51)$, and retrieval testing $(p=0.29)$. Eight rats died during surgery and two rats were excluded because of small DH lesions by histological verification. This yielded the following lesion groups: SH $(n=45)$, DH-Post $(n=27)$, and DHPre $(n=14)$.

The rats were submitted to three phases of training: fear conditioning, extinction, and retrieval testing. For this experiment, "context A" refers to the context in which fear conditioning occurred, and "context B" refers to the alternate context. The actual contexts in which fear conditioning, extinction, and testing occurred were counterbalanced across groups. For fear con- ditioning, rats were transported in squads of eight and placed in the conditioning chambers; chamber position was counterbalanced for each squad. The rats received five tone $(10 \mathrm{sec} ; 80 \mathrm{~dB}$; $2 \mathrm{kHz}$ )-footshock ( $1 \mathrm{sec} ; 1 \mathrm{~mA}$ ) trials (70-sec intertrial interval) beginning $3 \mathrm{~min}$ after being placed in the chambers. The rats were returned to their home cages $60 \mathrm{sec}$ after the final shock.

Then, $24 \mathrm{~h}$ after the conditioning session, rats were assigned to two groups that were extinguished to the tone either in the conditioning context (context A) or in a novel context (context $B)$. The extinction phase lasted $3 \mathrm{~d}$. On each extinction day, each rat spent 38 min in both context $\mathrm{A}$ and context $\mathrm{B}$; the order of the context exposure was counterbalanced. In the extinction context, rats received 30 tone-CS presentations $(10 \mathrm{sec} ; 80 \mathrm{~dB} ; 2 \mathrm{kHz}$; 60 -sec interstimulus interval) $3 \mathrm{~min}$ after placement in the context, while in the other context rats received no tone presentations. Approximately 3-4 h elapsed between placements in the two contexts each day.

Then, $7 \mathrm{~d}$ after the last extinction day, all rats were returned to a neutral context (context B) for renewal testing. Testing consisted of one 8-min continuous CS presentation $(80 \mathrm{~dB} ; 2 \mathrm{kHz}$; 60 -sec ISI) beginning $2 \mathrm{~min}$ after rats were placed in the context. The squads were counterbalanced for both lesion and test context, yielding a total of six groups in a $3 \times 2$ (lesion $\times$ test context) design. These six groups were SH/SAME, SH/DIFF, DH-Pre/ SAME, DH-Pre/DIFF, DH-Post/SAME, and DH-Post/DIFF. The labels SAME and DIFF referred to whether the CS was tested in a same context as the extinction context (SAME) or in a different context from the extinction context (DIFF).

\section{Histology}

Histological verification of lesion was performed after behavioral testing. Rats were perfused across the heart with physiological saline followed by a $10 \%$ formalin solution. After extraction from the skull, brains were post-fixed in $10 \%$ formalin solution for $2 \mathrm{~d}$, at which time the solution was replaced with a $10 \%$ formalin/ $30 \%$ sucrose solution until sectioning. Sections $(50 \mu \mathrm{m}$ thick) were cut on a cryostat $\left(-19^{\circ} \mathrm{C}\right)$, wet-mounted on microscope slides, and stained with $0.25 \%$ thionin for visualization of lesion.

\section{Data analysis}

For each session, the freezing data were transformed to a percentage of the total observations, a probability estimate that is amenable to analysis with parametric statistics. These probabilities of freezing were analyzed using ANOVA. Post hoc comparisons in the form of Fisher's PLSD tests were performed after a significant omnibus $F$-ratio. All data are represented as means \pm SEMs.

\section{Experiment 2: Pre-training electrolytic dorsal hippocampal lesions and renewal testing in the conditioning context}

\section{Subjects, surgery, and behavior apparatus}

The subjects were 32 adult male Long-Evans rats (200-224 g) obtained and housed as described in Experiment 1. All surgical procedures were the same as those described in Experiment 1. The conditioning chambers described in Experiment 1 comprised the behavior apparatus.

\section{Procedure}

All rats received pre-training lesions surgery aimed at the DH. The rats were allowed $7 \mathrm{~d}$ to recover after surgery. To equate the post-surgery recovery period of rats receiving post-extinction lesions in Experiment 1, rats with pre-training DH lesions were allowed $7 \mathrm{~d}$ of rest between extinction and retrieval testing. Three rats died during surgery, and this yielded the following lesion groups: $\mathrm{SH}(n=14)$ and DH-Pre $(n=15)$.

The rats were submitted to three phases of training: fear conditioning, extinction, and retrieval testing as described in Experiment 1 except that all rats were returned to the conditioning context (context A) for retrieval testing, and a total of four groups comprised the $2 \times 2$ (lesion $\times$ test context) design. These four groups were SH/SAME, SH/DIFF, DH-Pre/SAME, and DH-Pre/ 
DIFF. The labels SAME and DIFF referred to whether the CS was tested in a same context as the extinction context (SAME) or in a different context from the extinction context (DIFF).

\section{Histology and data analysis}

Histological verification of the lesions and data analysis were performed as described in Experiment 1.

\section{Acknowledgments}

This work was supported by a grant (R01065961) from the National Institute of Mental Health (S.M.). We thank Jennifer Hobin and Stephanie Jimenez for commenting on an earlier draft of the manuscript.

\section{References}

Addis, D.R., Moscovitch, M., Crawley, A.P., and McAndrews, M.P. 2004. Recollective qualities modulate hippocampal activation during autobiographical memory retrieval. Hippocampus. 14: 752-762.

Amorapanth, P., Nader, K., and LeDoux, J.E. 1999. Lesions of periaqueductal gray dissociate-conditioned freezing from conditioned suppression behavior in rats. Learn. Mem. 6: 491-499.

Anderson, M.I. and Jeffery, K.J. 2003. Heterogeneous modulation of place cell firing by changes in context. J. Neurosci. 23: 8827-8835.

Bouton, M.E. 1993. Context, time, and memory retrieval in the interference paradigms of Pavlovian learning. Psychol. Bull. 114: 80-99.

Burgess, N., Maguire, E.A., Spiers, H.J., and O'Keefe, J. 2001. A temporoparietal and prefrontal network for retrieving the spatial context of lifelike events. Neuroimage 14: 439-453.

Corcoran, K.A. and Maren, S. 2001. Hippocampal inactivation disrupts contextual retrieval of fear memory after extinction. J. Neurosci. 21: $1720-1726$.

. 2004. Factors regulating the effects of hippocampal inactivation on renewal of conditional fear after extinction. Learn. Mem. 11: 598-603.

Davachi, L., Mitchell, J.P., and Wagner, A.D. 2003. Multiple routes to memory: Distinct medial temporal lobe processes build item and source memories. Proc. Natl. Acad. Sci. 100: 2157-2162.

Eichenbaum, H. 2000. A cortical-hippocampal system for declarative memory. Nat. Rev. Neurosci. 1: 41-50.

Eichenbaum, H., Dudchenko, P., Wood, E., Shapiro, M., and Tanila, H. 1999. The hippocampus, memory, and place cells: Is it spatial memory or a memory space? Neuron 23: 209-226.

Eldridge, L.L., Knowlton, B.J., Furmanski, C.S., Bookheimer, S.Y., and Engel, S.A. 2000. Remembering episodes: A selective role for the hippocampus during retrieval. Nat. Neurosci. 3: 1149-1152.

Frankland, P.W., Cestari, V., Filipkowski, R.K., McDonald, R.J., and Silva, A.J. 1998. The dorsal hippocampus is essential for context discrimination but not for contextual conditioning. Behav. Neurosci. 112: $863-874$

Frohardt, R.J., Guarraci, F.A., and Bouton, M.E. 2000. The effects of neurotoxic hippocampal lesions on two effects of context after fear extinction. Behav. Neurosci. 114: 227-240.

Good, M. and Honey, R.C. 1991. Conditioning and contextual retrieval in hippocampal rats. Behav. Neurosci. 105: 499-509.

Good, M., de Hoz, L., and Morris, R.G. 1998. Contingent versus incidental context processing during conditioning: Dissociation after excitotoxic hippocampal plus dentate gyrus lesions. Hippocampus 8: $147-159$.

Hayman, R.M., Chakraborty, S., Anderson, M.I., and Jeffery, K.J. 2003. Context-specific acquisition of location discrimination by hippocampal place cells. Eur. J. Neurosci. 18: 2825-2834.

Hirsh, R. 1974. The hippocampus and contextual retrieval of information from memory: A theory. Behav. Biol. 12: 421-444.

Hobin, J.A., Goosens, K.A., and Maren, S. 2003. Context-dependent neuronal activity in the lateral amygdala represents fear memories after extinction. J. Neurosci. 23: 8410-8416.

Holdstock, J.S., Mayes, A.R., Roberts, N., Cezayirli, E., Isaac, C.L., O'Reilly, R.C., and Norman, K.A. 2002. Under what conditions is recognition spared relative to recall after selective hippocampal damage in humans? Hippocampus 12: 341-351.

Holdstock, J.S., Mayes, A.R., Gong, Q.Y., Roberts, N., and Kapur, N. 2005. Item recognition is less impaired than recall and associative recognition in a patient with selective hippocampal damage. Hippocampus 15: 203-215.

Holt, W.G. and Maren, S. 1999. Muscimol inactivation of the dorsal hippocampus impairs contextual retrieval of fear memory. J. Neurosci. 19: 9054-9062.

Honey, R.C. and Good, M. 1993. Selective hippocampal lesions abolish the contextual specificity of latent inhibition and conditioning. Behav. Neurosci. 107: 23-33.

Jeffery, K.J., Anderson, M.I., Hayman, R., and Chakraborty, S. 2004. A proposed architecture for the neural representation of spatial context. Neurosci. Biobehav. Rev. 28: 201-218.

Kennedy, P.J. and Shapiro, M.L. 2004. Retrieving memories via internal context requires the hippocampus. J. Neurosci. 24: 6979-6985.

Kim, J.J. and Fanselow, M.S. 1992. Modality-specific retrograde amnesia of fear. Science 256: 675-677.

Maguire, E.A., Frackowiak, R.S., and Frith, C.D. 1997. Recalling routes around London: Activation of the right hippocampus in taxi drivers. I. Neurosci. 17: 7103-7110.

Maren, S. 1998. Overtraining does not mitigate contextual fear conditioning deficits produced by neurotoxic lesions of the basolateral amygdala. J. Neurosci. 18: 3088-3097.

Maren, S. and Fanselow, M.S. 1997. Electrolytic lesions of the fimbria/fornix, dorsal hippocampus, or entorhinal cortex produce anterograde deficits in contextual fear conditioning in rats. Neurobiol. Learn. Mem. 67: 142-149.

Maren, S. and Holt, W. 2000. The hippocampus and contextual memory retrieval in Pavlovian conditioning. Behav. Brain Res. 110: 97-108.

Maren, S., Aharonov, G., and Fanselow, M.S. 1997. Neurotoxic lesions of the dorsal hippocampus and Pavlovian fear conditioning in rats. Behav. Brain Res. 88: 261-274.

Maren, S., Anagnostaras, S.G., and Fanselow, Michael. 1998. The startled seahorse: Is the hippocampus necessary for contextual fear conditioning? Trends Cogn. Sci. 2: 39-42.

Phillips, R.G. and LeDoux, J.E. 1992. Differential contribution of amygdala and hippocampus to cued and contextual fear conditioning. Behav. Neurosci. 106: 274-285.

Roberts, W.W., Dember, W.N., and Brodwick, M. 1962. Alternation and exploration in rats with hippocampal lesions. J. Comp. Physiol. Psychol. 55: 695-700.

Rudy, J.W. and O'Reilly, R.C. 2001. Conjunctive representations, the hippocampus, and contextual fear conditioning. Cogn. Affect. Behav. Neurosci. 1: 66-82.

Shull, R.N. and Holloway, F.A. 1985. Behavioral effects of hippocampal system lesions on rats in an operant paradigm. Brain Res. Bull. 14: 315-322.

Spear, N.E. 1973. Retrieval of memory in animals. Psychol. Rev. 80: $163-194$

Squire, L.R. and Zola, S.M. 1996. Structure and function of declarative and nondeclarative memory systems. Proc. Natl. Acad. Sci. 93: $13515-13522$.

Swanson, L.W. 1992. Brain maps: Structure of the rat brain. Elsevier, New York.

Tulving, E. and Thomson, D.M. 1973. Encoding specificity and retrieval processes in episodic memory. Psychol. Rev. 80: 352-373.

Vargha-Khadem, F., Gadian, D.G., Watkins, K.E., Connelly, A., Van Paesschen, W., and Mishkin, M. 1997. Differential effects of early hippocampal pathology on episodic and semantic memory. Science 277: 376-380.

Westbrook, R.F., Jones, M.L., Bailey, G.K., and Harris, J.A. 2000. Contextual control over conditioned responding in a latent inhibition paradigm. J. Exp. Psychol. Anim. Behav. Process. 26: $157-173$.

Wilson, A., Brooks, D.C., and Bouton, M.E. 1995. The role of the rat hippocampal system in several effects of context in extinction. Behav. Neurosci. 109: 828-836.

Winocur, G. 1990. Anterograde and retrograde amnesia in rats with dorsal hippocampal or dorsomedial thalamic lesions. Behav. Brain Res. 38: 145-154.

Yeshenko, O., Guazzelli, A., and Mizumori, S.J. 2004. Context-dependent reorganization of spatial and movement representations by simultaneously recorded hippocampal and striatal neurons during performance of allocentric and egocentric tasks. Behav. Neurosci. 118: 751-769.

Received January 18, 2005; accepted in revised form April 5, 2005. 


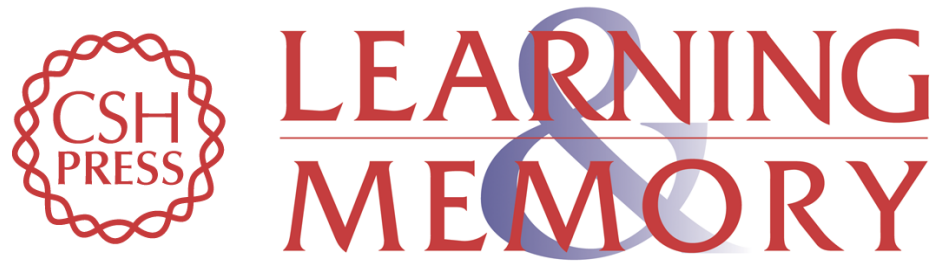

\section{Electrolytic lesions of the dorsal hippocampus disrupt renewal of conditional fear after extinction}

Jinzhao Ji and Stephen Maren

Learn. Mem. 2005, 12:

Access the most recent version at doi:10.1101//m.91705

References This article cites 42 articles, 13 of which can be accessed free at:

http://learnmem.cshlp.org/content/12/3/270.full.html\#ref-list-1

License

Email Alerting Receive free email alerts when new articles cite this article - sign up in the box at the Service top right corner of the article or click here. 